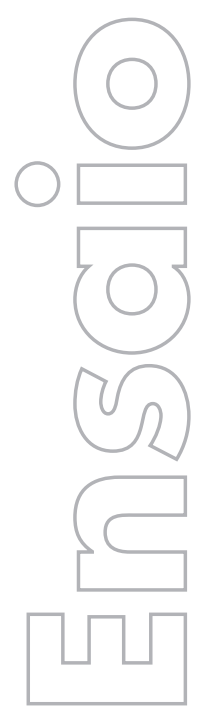

\title{
Mobilidade geográfica e acessibilidade: uma proposição teórica
}

\author{
Ricardo Abid Castillo \\ Unicamp
}

p. $644-649$

\section{revista}

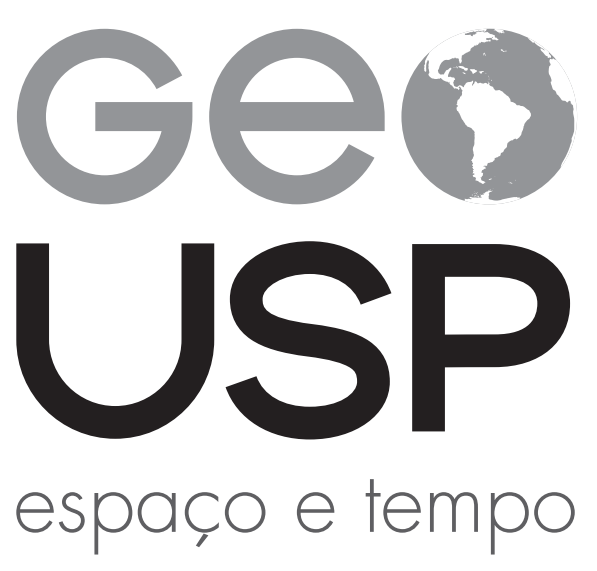

Volume $21 \bullet n^{\circ} 3$ (2017)
Como citar este artigo:

CASTILLO, R. A. Mobilidade geográfica e acessibilidade: uma proposição teórica. Geousp - Espaço e Tempo (Online), v. 21, n. 3, p. 644-649, dez. 2017. ISSN 2179-0892.

Disponível em: <http://www.revistas.usp.br/geousp/ article/view/140561>. doi: 10.11606/issn.2179-0892. geousp.2017.140561.

\section{(c) (i) (8)}

Este artigo está licenciado sob a Creative Commons Attribution 4.0 License. 


\section{Mobilidade geográfica e acessibilidade: uma proposição teórica}

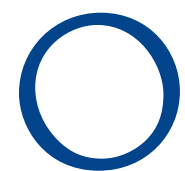

senso comum (Santos, B., 1988; Cunha, 2007) e algumas práticas profissionais associam, quase de imediato, mobilidade a migração e acessibilidade a adaptação do espaço urbano às necessidades de pessoas com diversos tipos de restrição. Também é habitual estabelecer correspondência sem permeio entre cada um desses termos e uma dada área do conhecimento, ou seja, mobilidade como um domínio sobretudo da demografia, enquanto a arquitetura e o urbanismo se encarregariam, ainda que não exclusivamente, da acessibilidade.

Essas assertivas são desenvolvidas ou diretamente questionadas neste texto. As alegações acima apenas servem como ponto de partida para uma proposta de reconstrução conceitual de ambos os termos, capaz de trazê-los para o âmbito da teoria geográfica e articulá-los dialeticamente. Para isso, é preciso superar, mas não apagar, seus sentidos cotidianos, outorgando-lhes operacionalidade e sintonia com o período histórico atual. Dar um primeiro passo nessa direção é o propósito deste pequeno ensaio.

Partindo da conjectura de que mobilidade espacial e acessibilidade são conceitos fundamentais para os estudos lastreados na geografia, sua abordagem dentro dessa área do conhecimento, no entanto, ainda reclama atenção. Em nossa proposição, entre outros possíveis, dois pressupostos de método são imediatamente requeridos: (1) a irredutibilidade entre sistemas de objetos e sistemas de ações como propriedade essencial do espaço geográfico e suas relações de contradição e complementaridade (Santos, M., 1996), e (2) a distinção entre possibilidades de ação, de um lado, e ações efetivas ou efetivamente realizadas, de outro (Santos, M., 1996; Santos, M; Silviera, 2001). É imprescindível reconhecer a coexistência entre as ações como presente e as ações como futuros possíveis ou prováveis para condensar uma explicação e conformar uma linguagem apropriada ao conhecimento de uma realidade socioespacial, instrumentalizar a pesquisa e a intervenção na realidade e classificar e relacionar fenômenos entre si.

Para alcançar o objetivo principal deste texto, poderíamos também recorrer ao conceito, oriundo da geografia quantitativa, de interações espaciais, entendido em seu sentido original como simples deslocamentos de corpos no espaço. Corrêa (2016) resgata o conceito livrando-o 
de sua conotação neopositivista e atribuindo-lhe a função de expressar os processos de circulação e comunicação e as transformações que necessariamente provocam nas frações do espaço que interagem (Cocco, 2011; Silveira; Cocco, 2013; Corrêa, 2016). Assim, podemos distinguir, de um lado, interações efetivamente realizadas, e, de outro, possibilidades de interação dadas pelas condições geográficas de cada momento histórico, porém impedidas de se realizar por circunstâncias políticas, econômicas e sociais desfavoráveis. Mais do que isso, o que estabelece, em última instância, um determinado uso do território (Santos, M., 1996) em detrimento de outros possíveis é o instável jogo de forças entre os agentes da regulação hibrida do território (Antas Jr., 2005, p. 208), ou seja, os representantes do Estado, do mercado e das organizações de solidariedade (Antas Jr., 2014). As noções de fluidez efetiva e fluidez potencial (Santos, M.; Silveira, 2001) convergem para essa ideia.

Cumpre ainda ressaltar que, no que tange ao termo mobilidade, os adjetivos espacial ou geográfico são necessários para distingui-lo de outras de suas formas, como a econômica, a social ou a do trabalho, esta última no sentido de mobilidade entre ramos produtivos (Gaudemar, 1977, p. 185).

\section{Um sentido mais abrangente de mobilidade espacial ou geográfica}

Seja social, econômica ou espacial, a mobilidade é um atributo do agente. De acordo com Ulian (2008, p. 208), a mobilidade espacial é a capacidade de um agente de se deslocar a pé ou por algum meio de transporte. Em nossa proposta, o conceito de mobilidade se amplia e, além da movimentação ou locomoção de si mesmo, envolve a capacidade do agente (indivíduo, empresa, instituição) de fazer movimentar bens ou mercadorias e também informação banal ou produtiva. Isso significa que o grau de mobilidade de um agente também se mede por seu poder político e/ou econômico de desencadear fluxos materiais e fluxos informacionais.

Essa concepção de uma mobilidade tripartite se caracteriza por duas categorias de variáveis: as internas (ou condições intrínsecas ao agente) e as externas (ou condições extrínsecas aos agentes). As variáveis internas são combinações de qualidades próprias, únicas para cada agente, que incluem desde saúde, idade e rendimento de um indivíduo até o grau de capitalização de uma empresa e seu poder de influência em decisões dos Estados a seu favor. As condições extrínsecas ou variáveis externas, por sua vez, que afetam diretamente a mobilidade espacial de cada agente, em cada fração do espaço e em diferentes escalas geográficas, são aquilo que entendemos por acessibilidade, cuja definição será apresentada mais adiante.

Em suma, a mobilidade espacial é a capacidade de um agente de movimentar-se a pé ou por algum meio de transporte e de fazer movimentar bens e informação; essa capacidade varia em função de uma série de atributos, dos quais os mais importantes são: (1) a condição econômica do agente e (2) a acessibilidade, isto é, as condições geográficas de cada fração do espaço e da escala de deslocamento.

As decorrências desta abordagem para os estudos geográficos podem ser promissoras, a começar pelas contradições entre, de um lado, a mobilidade da força de trabalho, em muitos casos cada vez mais precária e, de outro, a mobilidade do capital, cada vez maior. 1 A mobilida-

1 De acordo com Cocco (2011, p. 32), "a mobilidade do capital é intensificada e dotada de maior qualidade e eficiência, enquanto a mobilidade da força de trabalho na cidade é preterida em termos de qualidade, pela questão da baixa produtividade dos serviços de transporte público e conseguintemente, o baixo investimento no setor". 
de geográfica da força de trabalho, considerando tanto a produção quanto a reprodução social, está sujeita a diversas restrições, como a precariedade dos serviços de transporte público coletivo, tarifas elevadas de transporte, espraiamento das periferias urbanas em grandes extensões, dissociação entre o planejamento urbano e o planejamento de transportes (Vasconcellos, 1999; Silveira; Cocco, 2013) etc., como causa e consequência uns dos outros. Por sua vez, a mobilidade do capital financeiro e das mais diversas frações do capital produtivo (industrial, agropecuário, serviços produtivos) e serviços básicos está cada vez mais livre de obstáculos, em termos normativos e materiais. Faz parte ainda da mobilidade do capital a capacidade de seus agentes de fazer movimentar insumos, mercadorias e até mesmo plantas industriais, além, é claro, da informação.

É possível argumentar que a mobilidade da força de trabalho poderia contar com o revolucionário suporte das tecnologias da informação e comunicação (TIC), particularmente na forma de teletrabalho, o que, teoricamente, atenuaria os problemas devidos à precariedade do transporte público coletivo nos países periféricos e/ou dos congestionamentos nos horários de pico. Independentemente da evolução da participação do teletrabalho em relação ao trabalho presencial nas últimas décadas e de quanto a realidade de hoje confirma ou contradiz previsões dos anos 1980 e 1990, o fato é que, numa perspectiva mais particular, o advento e a difusão das TIC beneficiaram muito mais o capital, tornando-se em si mesmas um importante ramo produtivo.

De um ponto de vista mais amplo, Carr (2003) argumenta que as tecnologias da informação já passaram pela transição histórica da condição de tecnologias proprietárias para tecnologias infraestruturais, a exemplo das ferrovias e da energia elétrica; estão, portanto, cada vez mais banalizadas, fazendo parte das condições gerais de produção e chegando a ser consideradas pelo autor como commodities, por conta de sua padronização em escala mundial e de seus custos decrescentes. Assim, as TI têm ampliado consideravelmente a mobilidade de um número crescente de agentes de todos os tipos e de todas as classes sociais, transformando significativamente, por exemplo, o circuito inferior da economia urbana (Santos, M., 1978) em muitos lugares. Nesse sentido, compreender como essas tecnologias interferem na mobilidade geográfica do capital e da força de trabalho se torna uma pauta de pesquisa das mais relevantes na geografia.

Resta ainda mencionar que a mobilidade espacial de cada agente, sejam quais forem suas variáveis internas, muda em função do lugar, da região ou do território em que se encontra, o que nos remete à acessibilidade.

\section{Acessibilidade como atributo do espaço geográfico}

Sem concordar inteiramente com Vasconcellos (1999) e Ulian (2008), mas levando em conta suas contribuições, consideramos a acessibilidade, a partir dos dois pressupostos de método já mencionados, como um conjunto de meios materiais, regulações (normas) e serviços que, reunidos num dado subespaço, permitem oferecer à população local ou regional a possibilidade de se deslocar ou de fazer movimentar bens e informações para lugares específicos, centrais ou periféricos. Temos aí, novamente, uma definição tripartite. 
Trata-se, na verdade, das variáveis geográficas que interferem na mobilidade espacial de cada agente, expressas em condições infraestruturais (sistema viário, antenas de telefonia móvel, cabos de fibra óptica etc.), normativas (leis de trânsito, rodízio de veículos e horários de carga e descarga de cada município, formas de permissão ou concessão de serviços públicos de transportes e comunicações etc.) e de serviços (transporte público, banda larga de internet, entrega expressa, correios, telefonia móvel, logística etc.), que se apresenta a um determinado conjunto de agentes. De que maneira cada agente vai se valer dessa combinação, única em cada lugar, de infraestruturas, normas e serviços, dependerá de suas características intrínsecas ou variáveis internas, principalmente a econômica.

A acessibilidade é, portanto, um atributo dos lugares, das regiões e dos territórios e oferece melhores ou piores condições ao deslocamento de passageiros, bens e informações.

\section{Era da acessibilidade}

A partir do que foi discutido, podemos dizer de maneira bastante simples que um agente é mais ou menos móvel, enquanto um subespaço é mais ou menos acessível. A mobilidade espacial é única para cada agente, ainda que, hipoteticamente, todos tenham a sua disposição exatamente o mesmo arranjo geográfico em diversas escalas, isto é, que compartilhem de uma mesma combinação entre infraestruturas, normas e serviços de circulação e comunicação, para empregar os termos de Raffestin (1993). É também razoável afirmar que as variáveis interna e externa mais significativas para a ampliação da mobilidade de um agente são, respectivamente, a renda e as infraestruturas.

A combinação, em cada fração do território, de redes-suporte e redes-serviço (Dias, 2005) gera um conjunto de possibilidades de circulação-comunicação e de uso do território em cada momento histórico. Nesse sentido, a rede geográfica é uma intervenção no espaço cujo objetivo é criar acessibilidade, ampliar a mobilidade dos agentes e facilitar as interações espaciais. A passagem dessas possibilidades de circulação e de comunicação do estado de latência para o estado de existência e sua abrangência social dependem da política, do jogo de forças sociais que envolve o Estado, as empresas e as diversas formas de organização da sociedade civil.

Teoricamente, é possível associar o conceito de acessibilidade às noções de organização do território2 e de fluidez potencial ou virtual (Santos, M.; Silveira, 2001); simetricamente, o conceito de mobilidade espacial associa-se às noções de uso do território (Santos, M., 1996) e fluidez efetiva (Santos, M.; Silveira, 2001).3

2 Entendemos a organização do território como um conjunto de possibilidades de ação dadas pelas quantidades, qualidades, arranjo e distribuição de objetos naturais e técnicos, mais as normas que regem a propriedade e o acesso a essa base material, num compartimento político do espaço geográfico. Dessas possibilidades, aquelas que passam da condição de latência para a condição de existência, isto é, que de fato se realizam, são o uso do território. Por sua vez, a regulação do território compreende o jogo de forças (sociais, políticas, econômicas) que se estabelece entre Estado, mercado e sociedade civil organizada (Antas Jr., 2005), facilitando ou dificultando, impedindo ou franqueando determinados tipos de uso a determinados agentes.

3 "Pode-se distinguir entre uma fluidez virtual e uma fluidez efetiva do território. A fluidez virtual será medida em função da presença dos respectivos sistemas de engenharia. No entanto, o número e a densidade das vias podem não ser correspondidos pela freqüência e a densidade do seu uso. A presença dos meios produz a fluidez virtual, enquanto a fluidez efetiva é dada pelo uso efetivo dessas vias. No Brasil, a região Nordeste foi durante muito tempo um subespaço dotado de uma razoável rede rodoviária criada para minorar as conseqüências das secas, enquanto o uso dessa rede era limitado a certos momentos (por exemplo, as secas) e a certas funções. Um espaço pode ser denso quanto às vias, mas 
Com base nisso, é possível questionar o epíteto de "era da mobilidade" atribuído ao período histórico atual pela mídia, pelas universidades e também no mundo dos negócios. Há uma dupla contradição que se estabelece aí: (1) no que compete ao próprio deslocamento, a globalização seria mais bem designada como "era da acessibilidade" ou "era da imobilidade relativa", já que a difusão desenfreada de infraestruturas, a intermediação cada vez maior dos objetos técnicos sofisticados e o alargamento das escalas de ação têm criado um abismo entre os diferentes agentes em termos de mobilidade geográfica; para as populações de maneira geral, o desenvolvimento técnico e a difusão espacial dos transportes e das telecomunicações ampliam a fluidez potencial ao mesmo tempo em que diminuem, relativamente, a fluidez efetiva, e (2) a segunda contradição, totalmente relacionada à primeira, reside no fato de que, cada vez mais, agentes de todas as classes sociais acedem a dispositivos eletrônicos (computadores, tablets e smartphones) e às redes sociais, dotando-se, portanto, de uma mobilidade que, em períodos históricos anteriores, era inexistente ou inacessível. Essa nova dimensão de uma mobilidade geográfica mais plural ${ }^{4}$ ainda esconde muito de suas potencialidades sociais, culturais e econômicas, para propósitos tanto conservadores como emancipatórios.

reconhecimento do descompasso entre acessibilidade e mobilidade espacial se apresenta como um elemento de uma pauta de estudos geográficos mais amplos, que decorrem da diferença entre uso potencial e uso efetivo do território.

\section{Referências}

ANTAS JR., R. M. O complexo industrial da saúde no Brasil: uma abordagem a partir dos conceitos de circuito espacial produtivo e círculos de cooperação no espaço. GEOgraphia, v. 16, n. 32. p. 38-67, 2014.

ANTAS JR., R. M. Território e regulação: espaço geográfico, fonte material e não-formal do Direito. São Paulo: Humanitas, 2005.

CARR, N. G. TI doesn't matter. Harvard Business Review, n. 81, p. 41-49, may 2003.

$\mathrm{COCCO}, \mathrm{R}$. G. Interações espaciais e sistemas de transporte público: uma abordagem para Bauru, Marilia e Presidente Prudente. Dissertação (Mestrado em Geografia) - Faculdade de Ciências e Tecnologia, Universidade Estadual Paulista, Presidente Prudente, 2011.

CORRÊA, R. L. Processos, formas e interações espaciais. Revista Brasileira de Geografia, v. 61, n. 1, p. 127-134, 2016.

CUNHA, M. C. Relações e dissensões entre saberes tradicionais e saberes científicos. Revista USP, São Paulo, n. 75, p. 78-84, 2007.

DIAS, L. C. Os sentidos da rede: notas para discussão. In: DIAS, L. C.; SILVEIRA, R. L. L. (Org.). Redes, sociedades e territórios. Santa Cruz do Sul: Edunisc, 2005. p. 11-28.

4 Sem desconsiderar todos os tipos de desigualdades que caracterizam a rede mundial, tanto em termos de conectividade quanto de virtualidade (Evaso, 2006). 
EVASO, A. O espaço vertiginoso. Dissertação (Mestrado em Geografia Humana) Faculdade de Filosofia, Letras e Ciências Humanas, Universidade de São Paulo, São Paulo, 2006.

GAUDEMAR, J.-P. Mobilidade do trabalho e acumulação do capital. Lisboa: Estampa, 1977.

RAFFESTIN, C. Por uma geografia do poder. São Paulo: Ática, 1993.

SANTOS, B. S. Um discurso sobre as ciências na transição para uma ciência pós-moderna. Estudos Avançados, v. 2, n. 2, p. 46-71, 1988.

SANTOS, M. A natureza do espaço: técnica e tempo, razão e emoção. São Paulo: Hucitec, 1996.

SANTOS, M. Espaço dividido: os dois circuitos da economia urbana nos países subdesenvolvidos. Rio de Janeiro: Francisco Alves, 1978.

SANTOS, M.; SILVEIRA, M. L. O Brasil: território e sociedade no início do século XXI. Rio de Janeiro: Record, 2001.

SILVEIRA, M. R.; COCCO, R. G. Transporte público, mobilidade e planejamento urbano: contradições essenciais. Estudos Avançados, São Paulo, v. 27, n. 79, p. 41-53, 2013.

ULIAN, F. Sistemas de transportes terrestres de passageiros em tempos de reestruturação produtiva na região metropolitana de São Paulo. Tese (Doutorado em Geografia Humana) - Faculdade de Filosofia, Letras e Ciências Humanas, Universidade de São Paulo, São Paulo, 2008.

VASCONCELLOS, E. A. Circular é preciso, viver não é preciso: a história do trânsito na cidade de São Paulo. São Paulo: Annablume, 1999. 